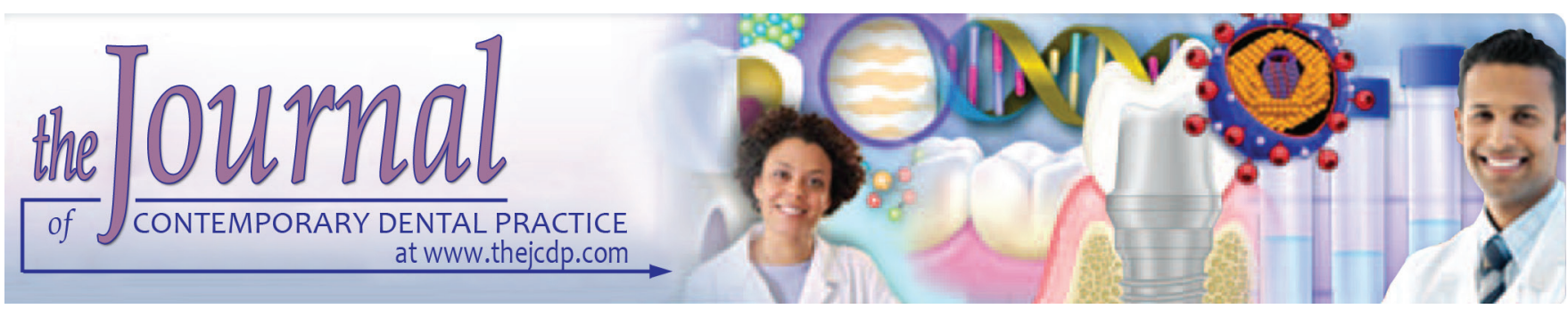

\title{
Evaluation of Bacteriological Profile in the Apical Root Segment of the Patients with Primary Apical Periodontitis
}

\author{
${ }^{1}$ Aravind Tatikonda, ${ }^{2} \mathrm{~N}$ Sudheep, ${ }^{3}$ Krishna P Biswas, ${ }^{4} \mathrm{~K}$ Gowtham, ${ }^{5}$ Sudarshan Pujari, ${ }^{6}$ Padam Singh
}

\begin{abstract}
Introduction: Apical periodontitis usually results from bacterial accumulation and contamination occurring in the root-canal system, and extending beyond the apical foramen to involve the periapical tissues. Literature has a paucity of the studies that stress on the division and analysis of the pulp canal segments. The reason for this disparity might be the technique used for collecting the samples from the pulp canals. Hence, we carried out the present study to evaluate the microbial flora in the apical part of the roots with necrotic pulp canals.
\end{abstract}

Materials and methods: The present study included the assessment of 40 freshly extracted teeth that had necrotized pulpal tissue along with the presence of periapical periodontal lesions. Removal of the soft tissue lesions attached to the root portion of the teeth along with apical periodontal lesions was done with the help of scalpel blade, after rinsing them with a sterile solution of saline. Thorough cleaning of the root surfaces was done with hydrogen peroxide followed by rapid disinfection with the help of sodium hypochlorite at varying concentrations. Sectioning of the root portion of all the specimens with the help of a disk was done perpendicular to the long axis of the teeth at a distance of roughly 5 to $6 \mathrm{~mm}$ from the teeth's apicalmost point. Cryotubes were used for transferring the specimens of apical portions containing $1 \mathrm{~mL}$ of buffer and were subjected

${ }^{1}$ Department of Periodontics, Triveni Institute of Dental Sciences Bilaspur, Chhattisgarh, India

${ }^{2}$ Department of Periodontics, Educare Institute of Dental Sciences, Malappuram, Kerala, India

${ }^{3}$ Department of Conservative Dentistry and Endodontics, Tamil Nadu Government Dental College and Hospital, Chennai, Tamil Nadu, India

${ }^{4}$ Department of Conservative Dentistry and Endodontics, Malla Reddy Dental College, Hyderabad, Telangana, India

${ }^{5}$ Department of Conservative Dentistry and Endodontics, Pandit Deendayal Upadhyay Dental College, Solapur, Maharashtra, India

${ }^{6}$ Department of Periodontology and Implantology, ITS Dental College, Greater Noida, Uttar Pradesh, India

Corresponding Author: Aravind Tatikonda, Department of Periodontics, Triveni Institute of Dental Sciences, Bilaspur Chhattisgarh, India, Phone: +919501544877, e-mail: aravindtk@ gmail.com to immediate frozen processing at a temperature of $-20^{\circ} \mathrm{C}$. A $10 \mathrm{~K}$-type file was used for the initial collection of the samples followed by subsequent incubation of the files and paper pints in the incubation cabinet. Subsequent deoxyribonucleic acid (DNA) extraction from the samples was done following the procedure described by Siqueira et al. Paster et al's modification of the reverse-capture checkerboard assay was used in the present study. Semiquantitative data were used for overcoming the difficulties arising due to obtaining the counts of the polymerase chain reaction (PCR)-based analysis of specimens.

Results: A positive result for the $16 \mathrm{~S}$ ribosomal ribonucleic acid ( $r R N A)$ gene primer was observed only in two examined specimens of all the samples of the apical portion of the root canals in the present study. Negative result was shown by all the control group specimens, which were sterile samples. Presence of bacteria was confirmed by PCR in 38 out of 40 examined specimens. Amount of bacterial taxa, out of these 24 samples, ranged up to 6. Pseudoramibacter alactolyticus, Porphyromonas endodontalis, Dialister oral species, Bacteroidetes species, Streptococcus species, Olsenella uli, Synergistes species, Fusobacterium nucleatum, Parvimonas micra, Treponema denticola, and Filifactor alocis were the specific species detected. Bacteroidetes species was the only species that were detected at levels at or above $10^{5}$. Heavy bacterial infections were noticed in more than $45 \%$ of the cases at the periradicular part of the root canals.

Conclusion: Microbial flora of the apical segment of the root with necrotized pulp tissue comprises a vast variety of pathogenic bacteria.

Clinical significance: For better prognosis of the treatment of such cases, adequate knowledge of the microbial flora of the root, especially the apical portion is necessary.

Keywords: Bacterial, Periodontitis, Polymerase chain reaction.

How to cite this article: Tatikonda A, Sudheep N, Biswas KP, Gowtham K, Pujari S, Singh P. Evaluation of Bacteriological Profile in the Apical Root Segment of the Patients with Primary Apical Periodontitis. J Contemp Dent Pract 2017;18(1):44-48.

Source of support: Nil

Conflict of interest: None 


\section{INTRODUCTION}

Bacterial pathogens invading and infecting the necrotized pulp canal system often caused contamination resulting in apical periodontitis. ${ }^{1}$ Areas in the vicinity and periphery of the apical part of the root portion of the tooth are the first tissues to get infected and develop pathology. The spectrum of diseases arising in and around the tissues of the apical foramen is referred to as apical periodontitis. Hence, the man etiologic role in these diseases is played by bacterial flora inhabiting the apical root portion. ${ }^{2}$ Literature has a paucity of studies that stress on the division and analysis of the pulp canal segments. The reason for this disparity might be the technique used for collecting the samples from the pulp canals. In methods routinely applied, the focus of the methodology is mainly on collecting the samples of the entire pulp canals. Therefore, the microbiological assessment in the past literature focuses mainly on the entire length of root canal rather than focusing on the apical segment. ${ }^{3}$ Hence, we carried out the present study to evaluate the microbial flora in the apical part of the roots with necrotic pulp canals. Cultivable species of bacterial taxa reported in the literature in various endodontic infections were taken into consideration while carrying out the assessment. ${ }^{4-9}$

\section{MATERIALS AND METHODS}

The present study was conducted in the Department of Periodontology of the institution and included assessment of 40 freshly extracted teeth. Only those teeth that had necrotized pulpal tissue along with the presence of periapical periodontal lesions were selected for the study. All the teeth samples were collected from the Department of Oral Surgery of the same institution following fresh extractions. Severe dental carious lesions were exhibited by the teeth along with no detectable evidence of marginal periodontitis. Ethical approval was taken from the institutional ethical committee after explaining to them the entire research protocol in written form. All the soft tissue lesions attached to the root portion of the teeth along with apical periodontal lesions were removed from the teeth with the help of a scalpel blade, after rinsing them with a sterile solution of saline. Thorough cleaning of the root surfaces was done with hydrogen peroxide followed by rapid disinfection with the help of sodium hypochlorite at varying concentrations. Careful and gentle cleaning of the root surfaces with these solutions was done with the help of sterile cotton swabs. Sectioning of the root portion of all the specimens, with the help of a disk, was done at $90^{\circ}$ to the long axis of the teeth at a distance of roughly 5 to $6 \mathrm{~mm}$ from the teeth's apicalmost point. After sectioning the teeth, again cleaning of the root surfaces was done with the help of previously used cleaning solutions.
Additional rubbing and cleaning of the root surfaces was done with sodium thiosulfate at $5 \%$ concentration. Sterile dry paper pints were used for drying the externally cleaned root surfaces. These specimens were further subjected to polymerase chain reaction (PCR) analysis with the help of bacterial universal primers. Cryotubes were used for transferring the specimens of the apical portions containing $1 \mathrm{~mL}$ of buffer and were subjected to immediate frozen processing at a temperature of $-20^{\circ} \mathrm{C}$.

\section{Sample Collection and DNA Analysis}

Thawing of the apical segments was done at $37^{\circ} \mathrm{C}$ while holding them with sterile forceps with soft ends. Initial collection of the samples was done using a $10 \mathrm{~K}$-type file (Dentsply), which involved introduction of the file in the pulp space until it reached the visible portion of the apical foramen in a gently filing motion. For drying the root canal, subsequent introduction of paper points was done into the canal spaces. Cryotubes containing the TE buffers were used for the subsequent incubation of the files and paper pints in the incubation cabinet. Subsequent deoxyribonucleic acid (DNA) extraction from the samples was done following the procedure described by Siqueira et al. ${ }^{10}$ For making the control group, several bacterial DNA was chosen as previously described in the literature. ${ }^{11}$ Paster et al's modification of the reverse-capture checkerboard assay was used in the present study. ${ }^{5,12}$ It involved extraction of whole genomic-based DNA extracts from the specimens, and further using them as templates in a ribosomal ribonucleic acid (rRNA) gene-based PCR system. The $8 \mathrm{f} / 519 \mathrm{r}$ and $515 \mathrm{f} / 1492 \mathrm{r}$ primers were mixed, and the labeled PCR products that were obtained were further mixed in equal quantities for use for the assessment of the 28 levels of the bacterial taxa by the reverse-capture checkerboard analysis. Semiquantitative data were used for overcoming the difficulties arising due to obtaining the counts of PCR-based analysis of specimens. The data were categorized as shown in Table $1 .^{5}$

\section{RESULTS}

In the present study, we observed positive results for the $16 \mathrm{~S}$ rRNA gene primer only in two examined specimens of all the samples of the apical portion of the root canals. Negative result was shown by all the control group specimens, which were sterile samples. Presence of

Table 1: Categorization of the bacterial levels

\begin{tabular}{ll}
\hline Category & Parameter \\
\hline Absence or below the level of detection & $<10^{5}$ bacteria \\
Approx. $10^{5}$ bacterial level & $>10^{5}$ to $<10^{6}$ bacteria \\
Approx. $10^{6}$ bacterial level & $>10^{6}$ bacteria \\
Heavy infection & $>10^{5}$ Bacterial levels \\
\hline
\end{tabular}


bacteria was confirmed by PCR in 38 out of 40 examined specimens. No significant inhibition of the PCR reaction was detected, and also DNA contaminants that could be detected were absent on the external radicular surfaces. In the reverse-capture checkerboard analysis, positivity for bacteria presence was demonstrated by 38 specimens with the help of universal probes. Out of 56 samples tested by taxon-specific probes, 22 specimens were observed to be reactive with apical pulp canal specimens. Positivity for at least one test probe was shown by 24 cases. Amount of bacterial taxa, out of these 24 samples, ranged up to 6 . Pseudoramibacter alactolyticus, Porphyromonas endodontalis, Dialister oral species, Bacteroidetes species, Streptococcus species, Olsenella uli, Synergistes species, Fusobacterium nucleatum, Parvimonas micra, Treponema denticola, and Filifactor alocis were the specific species detected (Graph 1). The only species that were detected at levels at or above $10^{5}$ were the Bacteroidetes species. Heavy bacterial infections were noticed in more than $45 \%$ of the cases at the periradicular part of the root canals.

\section{DISCUSSION}

Prevention of pulp and periradicular diseases is the main goal of endodontic therapy. A thorough understanding of the etiopathogenesis of the diseases is necessary to achieve this goal. Long before the invasion of pulpal tissue occurs by bacterial pathogens, initiation of inflammatory process occurs due to deep carious lesions. ${ }^{13-15}$ Reversible inflammatory processes in the context of inflammation of the pulp refer to those pathologic conditions that have not invaded the pulp tissue, and therefore, no endodontic therapy is required for their treatment. As long as the superficial layers of the pulp remain vital even after invasion by the bacteria, they are considered as bacteria free. In the necrotic pulp canals, inflammation of the periapical tissues by pathogenic microorganisms is known as apical periodontitis. ${ }^{16}$ Prevalence of microorganisms in the root canal in the posttreatment phase worsens the prognosis of the disease.${ }^{17-19}$ Nevertheless, effective elimination of the pathogenic microorganisms in the pulp canal determines the healing of primary apical periodontitis that, in turn, depends on the effective elimination of the causative agents in the root canal system. ${ }^{20}$

In the present study, we examined the apical segments of the infected root canals of the teeth with apical periodontitis of the 40 samples of freshly extracted teeth using 28 bacterial taxa levels of reverse-capture checkerboard DNA-DNA hybridization assay. Multiple and a wide range of bacterial species can be detected simultaneously with the help of this method. Apart from this, this technique also offers the additional advantage of exhibiting high specificity. ${ }^{5,12}$ A heavy infection of the total bacteria was exhibited in approximately $50 \%$ of the specimens. Bacteroidetes clone X083 and Synergistes clone BA121 were the only taxa that were detectable at levels beyond $10^{5}$ (Graph 1$)$. These species have been reported to be detected and isolated in various other human sites also. ${ }^{11,21}$ Wang et $\mathrm{al}^{22}$ investigated the primary bacterial flora and the localization of extraradicular biofilm in patients with persistent apical periodontal lesions. From the results, they concluded that on the external root surfaces of the teeth treated earlier and still had persistence of periapical lesions, extraradicular biofilm is seen. Further, for the formation of this biofilm, Actinomyces species oral and Propionibacterium are most probably a contributory factor. Kumar et $\mathrm{al}^{23}$ assessed the presence of fungal species in root canaltreated teeth with periodontal lesion to elucidate their role in the failure of root canal therapy. They evaluated 20 mandibular molars for the presence of Candida organisms and concluded that cause of failure of root canal therapy could be due to Candidal contamination. They further emphasized on the importance of isolation and use of

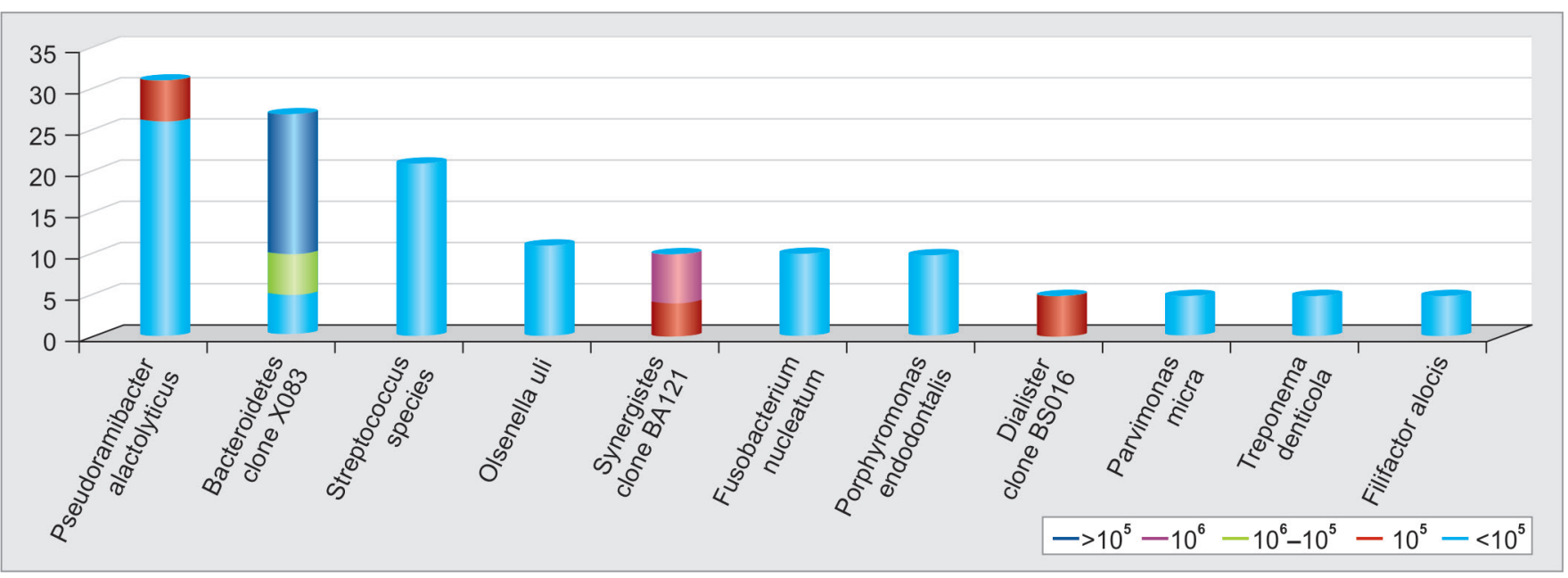

Graph 1: Frequency of detection of various bacterial taxa in the periapical specimens of the apical periodontitis cases with necrotic pulp canals 
irrigants during the endodontic procedure to avoid contamination by fungal microorganisms. Vengerfeldt et $\mathrm{al}^{24}$ evaluated the root canals of the human teeth to retrieve the root canal microbial communities in antibiotic-naive patients. They collected samples from 12 deciduous teeth and on the basis of the V6 hypervariable region of the $16 \mathrm{~S}$ ribosomal RNA gene, profiled their microbial community. Through the results of their study, they gave an in-depth picture and view of the microbial data of the periradicular tissues, further throwing light on the presence of highly polymicrobial communities in the study groups. Tennert et $\mathrm{al}^{25}$ evaluated the microbial picture of primary and secondary root canal infections of patients undergoing root canal therapy. They took three sequential samples with sterile paper points from the pulp canal of over 20 patients of German origin and isolated the microorganisms from them with the help of biochemical analysis. By analyzing the results, they found new bacterial combinations, and further, they correlated these findings with clinical and radiographic results, in particular with the cases of chronic apical abscesses. In addition, in the root canal of the German patients, they detected Moraxella osloensis. Beus et $\mathrm{al}^{26}$ conducted a randomized clinical study prospectively in order to comparatively evaluate the results of a nonactivated single-irrigation protocol with a passive ultrasonic multi-irrigation protocol in providing bacteriafree canals. They assessed 50 patients with a posterior tooth requiring primary root canal treatment for apical periodontitis. From the results, they concluded that observation of a high frequency of negative cultures at the first follow-up time is most probably due to the raised volume and depth of irrigation in comparison with the protocols reported earlier in the literature. Vera et $\mathrm{al}^{27}$ evaluated the microbial picture of the pulp canals of mesial roots of mandibular molars with primary apical periodontitis after a single sitting or two sittings of root canal therapy. They instrumented mesial pulp canals either by combination of K3 and LightSpeed instruments or with the help of ProTaper system, along with $5 \% \mathrm{NaOCl}$ irrigation. One week after root canal instrumentation, teeth were extracted and evaluated for histobacteriological profiling. From the results, they concluded that with the help of interappointment medication with calcium hydroxide in the two-sitting procedure, improved microbiological status of the root canal system is achieved in comparison with the one-visit protocol.

\section{CONCLUSION}

From the above results, the authors conclude that microbial flora of the apical segment of the root with necrotized pulp tissue comprises a vast variety of pathogenic bacteria. For carrying out proper therapeutic treatment and for good prognosis, adequate knowledge of the microbial flora of the root, especially the apical portion, is necessary.

\section{REFERENCES}

1. Baumgartner, J.C.; Hutter, J.W.; Siqueira, J.F., Jr. Endodontic microbiology and treatment of infections. In: Cohen, S.; Hargreaves, K.M.; editors. Pathways of the pulp. 9th ed. St. Louis: Mosby/Elsevier; 2006. p. 580-607.

2. Siqueira JF Jr. Reaction of periradicular tissues to root canal treatment: benefits and drawbacks. Endod Topics 2005 Mar;10(1):123-147.

3. Sathorn C, Parashos P, Messer HH. How useful is root canal culturing in predicting treatment outcome? J Endod 2007 Mar;33(3):220-225.

4. Rôças IN, Hulsmann M, Siqueira JF Jr. Microorganisms in root canal-treated teeth from a German population. J Endod 2008 Aug;34(8):926-931.

5. Rôças IN, Siqueira JF Jr. Root canal microbiota of teeth with chronic apical periodontitis. J Clin Microbiol 2008 Nov;46(11):3599-3606.

6. Sakamoto M, Rôças IN, Siqueira JF Jr, Benno Y. Molecular analysis of bacteria in asymptomatic and symptomatic endodontic infections. Oral Microbiol Immunol 2006;21(2):112-122.

7. Munson MA, Pitt-Ford T, Chong B, Weightman A, Wade WG. Molecular and cultural analysis of the microflora associated with endodontic infections. J Dent Res 2002 Nov;81(11): 761-766.

8. Siqueira JF Jr, Rôças IN. Exploiting molecular methods to explore endodontic infections: part 2-redefining the endodontic microbiota. J Endod 2005 Jul;31(7):488-498.

9. Siqueira JF Jr, Rôças IN. The microbiota of acute apical abscesses. J Dent Res 2009 Jan;88(1):61-65.

10. Siqueira JF Jr, Rôças IN, Alves FR, Santos KR. Selected endodontic pathogens in the apical third of infected root canals: a molecular investigation. J Endod 2004 Sep;30(9):638-643.

11. Siqueira JF Jr, Rôças IN. Uncultivated phylotypes and newly named species associated with primary and persistent endodontic infections. J Clin Microbiol 2005 Jul;43(7):3314-3319.

12. Paster BJ, Bartoszyk IM, Dewhirst FE. Identification of oral streptococci using PCR-based, reverse-capture, checkerboard hybridization. Methods Cell Sci 1998 Mar;20(1):223-231.

13. Pashley DH. Dynamics of the pulpo-dentin complex. Review. Crit Rev Oral Biol Med 1996;7(2):104-133.

14. Bergenholtz G. Pathogenic mechanisms in pulpal disease. J Endod 1990 Feb;16(2):98-101.

15. Jontell M, Okiji T, Dahlgren U, Bergenholtz G. Immune defense mechanisms of the dental pulp. Crit Rev Oral Biol Med 1998;9(2):179-200.

16. Kakehashi S, Stanley HR, Fitzgerald RJ. The effects of surgical exposures of dental pulps in germfree and conventional laboratory rats. J South Calif Dent Assoc 1966 Sep;34(9):449-451.

17. Engström B. The significance of enterococci in root canal treatment. Odontol Revy 1964;15:87-106.

18. Sjögren U, Figdor D, Persson S, Sundqvist G. Influence of infection at the time of root filling on the outcome of endodontic treatment of teeth with apical periodontitis. Int Endod J 1997 Sep;30(5):297-306.

19. Katebzadeh N, Sigurdsson A, Trope M. Radiographic evaluation of periapical healing after obturation of infected root canals: an in vivo study. Int Endod J 2000 Jan;33(1):60-66. 
20. Chugal NM, Clive JM, Spangberg LS. A prognostic model for assessment of the outcome of endodontic treatment: effect of biologic and diagnostic variables. Oral Surg Oral Med Oral Pathol 2001 Mar;91(3):342-352.

21. Vartoukian SR, Palmer RM, Wade WG. The division "Synergistes." Anaerobe 2007 Jun-Aug;13(3-4):99-106.

22. Wang J, Jiang Y, Chen W, Zhu C, Liang J. Bacterial flora and extraradicular biofilm associated with the apical segment of teeth with post-treatment apical periodontitis. J Endod 2012 Jul;38(7):954-959.

23. KumarJ,SharmaR,SharmaM,PrabhavathiV,PaulJ,ChowdaryCD. Presence of Candida albicans in root canals of teeth with apical periodontitis and evaluation of their possible role in failure of endodontic treatment. J Int Oral Health 2015 Feb;7(2):42-45.

24. Vengerfeldt V, Špilka K, Saag M, Preem JK, Oopkaup K, Truu J, Mändar R. Highly diverse microbiota in dental root canals in cases of apical periodontitis. J Endod 2014 Nov;40(11): 1778-1783.

25. Tennert C, Fuhrmann M, Wittmer A, Karygianni L, Altenburger MJ, Pelz K, Hellwig E, Al-Ahmad A. New bacterial composition in primary and persistent/secondary endodontic infections with respect to clinical and radiographic findings. J Endod 2014 May;40(5):670-677.

26. Beus C, Safavi K, Stratton J, Kaufman B. Comparison of the effect of two endodontic irrigation protocols on the elimination of bacteria from root canal system: a prospective, randomized clinical trial. J Endod 2012 Nov;38(11): 1479-1483.

27. Vera J, Siqueira JF Jr, Ricucci D, Loghin S, Fernández N, Flores B, Cruz AG. One-versus two-visit endodontic treatment of teeth with apical periodontitis: a histobacteriologic study. J Endod 2012 Aug;38(8):1040-1052. 